\title{
Water saturation on Albian carbonates reservoirs—ancient Brazilian oil fields
}

\section{Maria Gabriela Castillo Vincentelli and Sergio António Caceres Contreras}

FUNDUNESP_Universidade Estadual Paulista, Rio Claro, Brazil

E-mail: g_vicentelli@yahoo.es and sacaceresc@gmail.com

Received 25 June 2015, revised 11 August 2016

Accepted for publication 14 September 2016

Published 7 October 2016

\begin{abstract}
One of the main objectives for petroleum exploration is to quantify the reservoir's oil in place; usually this process is based on a petrophysical evaluation that, among other parameters, the reservoir water saturation $\left(S_{\mathrm{w}}\right)$ must be calculated, because it represents the main factor for determining hydrocarbon saturation $\left(S_{\mathrm{h}}\right)$. Classical petrophysical analysis includes the use of the water saturation's resistivity $\left(R_{\mathrm{W}}\right)$ and two main constants (for Archie saturation), as well as cementation $(m)$ and tortuosity $(a)$; both of which are obtained from laboratory plug/ cores measurements. However, in the case of ancient Albian carbonate reservoirs (Brazil), this kind of data is not available for a fully water saturated reservoir, and as a consequence, we proposed to apply a logarithmic graphic solution of the main Archie's equations to determine these main factors using a linear regression based on wire logs. As result, an $R_{\mathrm{W}}$ was confirmed at $127 \mathrm{Kppm}$ of $\mathrm{NaCl}$ for Quissamã Formation, $m=1.071$ and $a=0.87$. Finally, the value of ' $m$ ' is more affected by the pore and size configuration, and the ' $a$ ' value appears to be a logical answer for carbonates reservoir with high porosity.
\end{abstract}

Keywords: petrophysics for carbonates, cementation, tortuosity, water formation resistivity, Archie's core estimation parameters

(Some figures may appear in colour only in the online journal)

\section{Introduction}

The Albian carbonate reservoirs in Brazilian offshore basins represent a good opportunity for oil re-exploration. It is known that some oil fields, like Linguado and Garoupa, among others, are recognized as good oil producers from the Macaé Group (Albian), but they are considered ancient oil fields because the production began at least 40 years ago.

Nowadays, the oil re-exploration in the Brazilian Albian carbonates would represent new economic opportunities in the Pos-Salt stratigraphic sequence. It is necessary to determine well parameters, like cementation $(m)$ and tortuosity $(a)$, that impact directly on the calculation of the reservoir hydrocarbon saturation, and as consequence the actual hydrocarbon potential of a specific play will be evaluated with less geological uncertainty and more volumetric accuracy.

In Brazilian Albian carbonate reservoirs the exploratory play is related to carbonates banks that show oncoids and ooids as the geological facies of Quissamã Formation. These facies are distributed in a modal and bimodal fabric that is favorable to the permeability and porosity interconnected reservoir system.

On the other hand, the petroleum economic evaluation, for a geological prospect, depends on an interdisciplinary analysis like seismic interpretation to define the geometry of the prospect and petrophysics, among others, that describes the physical properties of the reservoir based on several variables like: porosity, net to gross, fluid saturation, etc. All of these rock properties are mainly calculated from geophysical data (wirelogs and seismic data). In this sense, the reservoir hydrocarbon saturation $\left(S_{\mathrm{h}}\right)$, obtained from petrophysical evaluation, represents the volume of fluid saturation used for the hydrocarbon volume calculation. In other words, it is one of the most important values for performing a prospect economic evaluation, because $S_{\mathrm{h}}$ represents the saturation of the hydrocarbon in place.

The main constraint, performed on this paper, is that the saturation equation to be applied is the Archie equation (1941). 
The reason we follow this assumption is the same as for other geoscientists, the cores obtained from the Brazilian carbonate Albian's section do not contain shale. Nowadays the unique saturation equation available to perform this calculation is the selected one, we believe that if we perform the same test of Archie (1941) on carbonates cores and transmit electrical current through them, this will verify if the geological assumption is right or even calibrate the original equation.

Although the process to calculate $S_{\mathrm{h}}$ is very well known for siliciclastics reservoir rocks, the main propose here is to present a process to calculate $S_{\mathrm{h}}$ in Albian Brazilian carbonatic reservoirs, where the cementation $(m)$ and tortuosity $(a)$ factors, measured in the lab, are not available on the full water saturated zone for researchers or even for operator companies.

The values of ' $a$ ' and ' $m$ ' for carbonates reservoirs are quite different than for siliciclastic, and their measurement depends on a large number of factors, such as grain shape, shorting, pore configuration, size, tortuosity, etc. The traditional way to calculate these factors is to acquire plugs on the full saturated water reservoir zone and measure in the lab properties like electrical conductivity through the core plug with fluid, the goal being to determine these parameters. The problem is that there are a lot of oil fields on the carbonate reservoirs where these kinds of laboratory measures are not available, like Albian ancient reservoirs in the Brazilian basins.

If the petrophysical community accepts that the original saturation equations (Archie 1941, Simandoux 1963, Waxman and Smits 1968, etc) are related to siliciclastic reservoirs, an adjustment of the saturation calculation to carbonate reservoirs is necessary. In this sense, we believe the right way is to perform the same laboratory tests that Archie (1941) performed, and as result obtain an empirical relationship between porosity, electrical conductivity and brine saturation of rock.

The Archie equation is very well applied on siliciclastic reservoirs with low volume of shale and high porosity $(>20 \%)$, because of this most of the companies and researchers are using the Archie relationship to calculate the hydrocarbon saturation on carbonates reservoirs, but is this a good way to calculate saturation on carbonates reservoirs?; maybe not. Some experiments comparing the water saturation using Archie's equation and the actual production from oil fields show an approximately $25 \%$ difference (Teixeira et al 2015). It is possible that this difference is the result of the use of the ' $a$ ' and ' $m$ ' factors widely applied for carbonate rocks with low porosity ( $m=2$ and $n=1$ ), causing high dispersion between the calculated water reservoir's saturation $\left(S_{\mathrm{w}}\right)$ and the confirmed production's reservoir history, when the traditional parameters for high porosities carbonates reservoirs are applied.

In order to obtain the reservoir water saturation, an important value like the water formation resistivity $\left(R_{\mathrm{W}}\right)$ is necessary. For the Campos basin at the Albian stratigraphic level, the $R_{\mathrm{w}}$ value was measured at the well RJS-0029-RJ in $127 \mathrm{Kppm}$ of $\mathrm{NaCl}$.

The main two values ( $a$ and $m$ ) were obtained from well logs evaluated on the water saturated zone using Archie's equation. Even when we do not apply the core Archie parameter estimation method (CAPE), as proposed by Maute et al (1992), the obtained $a$ and $m$ values are justified by the principle explained in the original paper as an analytical method that 'determine Archie's parameters $m, n$ and optionally $a$ by minimizing the error between computed water and measured saturations'.

There are at least two factors that justify the application of this method based on the CAPE approximation defined previously: the first one is related to the absence of petrophysical core measures in the full water saturated Brazilian Albian reservoirs, and the second is that the water resistivity $\left(R_{\mathrm{w}}\right)$ in the main reservoir was measured in a few wells and in a different reservoir than the main dataset used in this job. As a consequence an approximation or estimation done from wirelogs will help geocientists to better estimate the volume of hydrocarbon in place contained on Albian Brazilian reservoirs (carbonates).

However, there are a lot of ancient oil fields that do not contain petrophysical cores studies. It is possible to calculate the fluid saturation because the database of these fields is formed by basic well logs, as well as gamma ray, density, neutron and resistivity that allow the calculation of tortuosity $(a)$ and cementation $(m)$ parameters.

The measurement of core Archie parameters and its estimation (CAPE) have been applied along carbonates oil fields around the world (Hamada et al 2010, Sharifi et al 2012), and the result is particular for each carbonate bank evolution. Currently, researchers are working on a unique petrophysical answer for carbonate reservoirs, but it is still too early to apply a particular result for different carbonates fields.

In additional, it is important to mention that in well cores is was proved that the measured values for the cementation exponent $(\mathrm{m})$ are very variable in complex lithologies, and it is considered that this variation is very large for carbonates reservoirs. In the case of the tortuosity factor, the value of ' $a$ ' depends on the connectivity of the reservoir pores.

\section{Objectives}

The main objective is to calculate the values of the cementation factor $(m)$, and tortuosity factor $(a)$ on Albian Carbonates rocks from ancient oil fields of the Campos Basin in Brazil. Because these factors are not available for the evaluated stratigraphic level for a fully water saturated reservoir, the goal is to apply a logarithmic graphic solution of the main Archie's equations to determine these main parameters using a linear regression based on wire logs. It is expected that the determination of these values $(a$ and $m$ ) will be less the saturation uncertainty related to carbonates reservoirs along Albian hydrocarbon opportunities.

\section{Database}

Twenty one wells were evaluated that contain logs of resistivity (ILD), porosity (neutron) and density (RHOB), among others. These wells are from two ancient carbonates oil fields and statistically represent the Albian carbonate reservoir. 


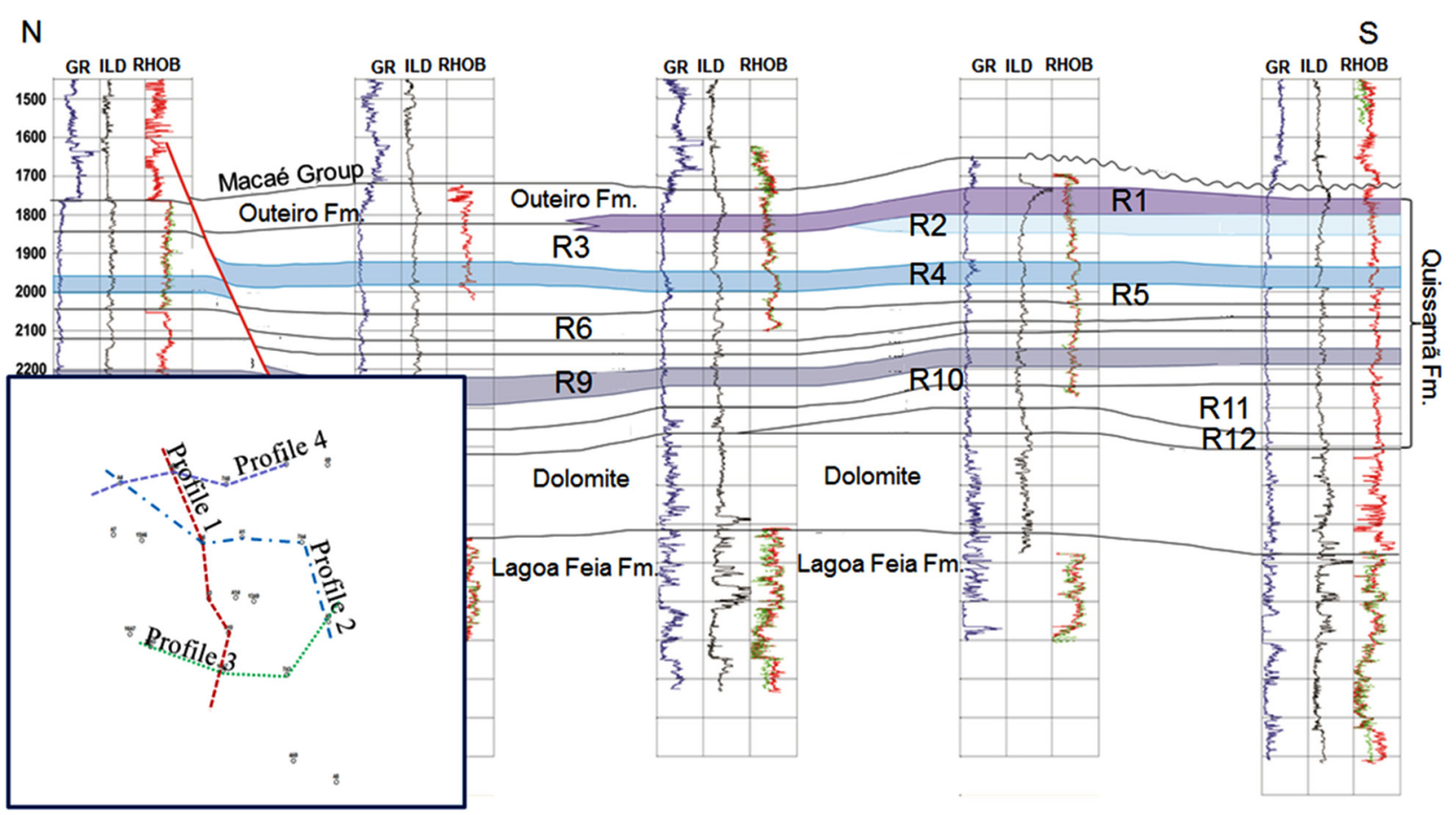

Figure 1. Well correlation along the Macaé Group (Quissamã reservoir for the Campos Basin). The main figure shows twelve (12) identified potential reservoir levels at the evaluated area, and in the figure below, the well distribution in the oil field. The color lines identify the main geological profile directions of the well correlation sections performed in this work. The profile shown here (red line) is the number 1 .

The $R_{\mathrm{w}}$ value for calibration was obtained from the well RJS-0029-RJ, when the chemical composition of the water's formation, in order to get $R_{\mathrm{w}}$, was measured in $127 \mathrm{Kppm}$ of $\mathrm{NaCl}$, which means $R_{\mathrm{w}}=0.031$ ohm_m at $158^{\circ} \mathrm{F}$ in the main reservoir (upper Quissamã). It is important to mention that the error related to the measure of the $\mathrm{NaCl}$ content is lower than $1 \%$ for this reservoir water condition (salt water), and as a consequence the calculated $R_{\mathrm{w}}$ is almost the same for petrophysical analyses.

\section{Method}

First of all, twelve stratigraphic reservoir levels for AlbianQuisamã formation were correlated along 21 wells, distributed in four main geological profiles along the study area, as show in figure 1.

The main reservoir levels with full water saturated, present in most of wells, were selected for analysis (10 of the 12) as the Archie principle. It was assumed that the formation factor $(F)$ is the same at the same reservoir, independently of the fluid content inside them; in this way, the $F$ factor was calculated for each one. In addition, if the resistivity index (RI) is considered as well as described by Archie $\mathrm{RI}=R_{\mathrm{t}} / R_{\mathrm{O}}=1 / S_{\mathrm{w}}^{n}$, it is possible to assume that $R_{\mathrm{t}}=R_{\mathrm{o}}$ on the zone full water saturated because $S_{\mathrm{w}}^{n}=1$.

The formation factor $(F)$ is defined as:

$$
F=R_{\mathrm{t}} / R_{\mathrm{w}}=R_{\mathrm{o}} / R_{\mathrm{w}}
$$

where:

$R_{\mathrm{t}}=$ reservoir total resistivity

$R_{\mathrm{O}}=$ resistivity on the full water zone
$R_{\mathrm{w}}=$ water reservoir resistivity.

On the other hand, $F$ was defined as:

$$
F=a / \emptyset^{m}
$$

where:

$$
\begin{aligned}
& a=\text { tortuosity factor } \\
& \phi=\text { reservoir porosity } \\
& m=\text { cementation factor. }
\end{aligned}
$$

With the objective of contextualized use of these main factors to calculate water saturation $\left(S_{\mathrm{w}}\right)$, the equation of $S_{\mathrm{w}}$ is defined by Archie as:

$$
S_{\mathrm{w}}^{n}=\left(a / \varnothing^{m}\right) *\left(R_{\mathrm{w}} / R_{\mathrm{t}}\right)
$$

with the aim of solving the equation system the ' $n$ ' factor related to the saturation exponent was set to 2 , the default value.

For all the reservoirs, $R_{\mathrm{O}}$ was obtained as the mode resistivity value at formation temperature $\left(t_{\mathrm{f}}\right)$ from the resistivity $\log$ (ILD). In figure 2 the full water saturated reservoir related to the level R4 is shown, as a result of the mathematical operation $F$ is 4,6 , where $R_{\mathrm{W}}=0.0377$ ohm_m at formation temperature. The calculated reservoir temperature is $136{ }^{\circ} \mathrm{F}$ and it considers a local thermal gradient from the well temperature measured on the sea bottom and at the total well's depth.

The formation factor $(F)$ was calculated from ten water reservoirs levels and it was determined for each well using the $R_{\mathrm{w}}$ measured on the well RJS-0029-RJ. The resistivity value was adjusted by the reservoir temperature as a function of the depth using the Schlumberger resistivity of $\mathrm{NaCl}$ water solution chart (Gen-6, Schlumberger 2009). 

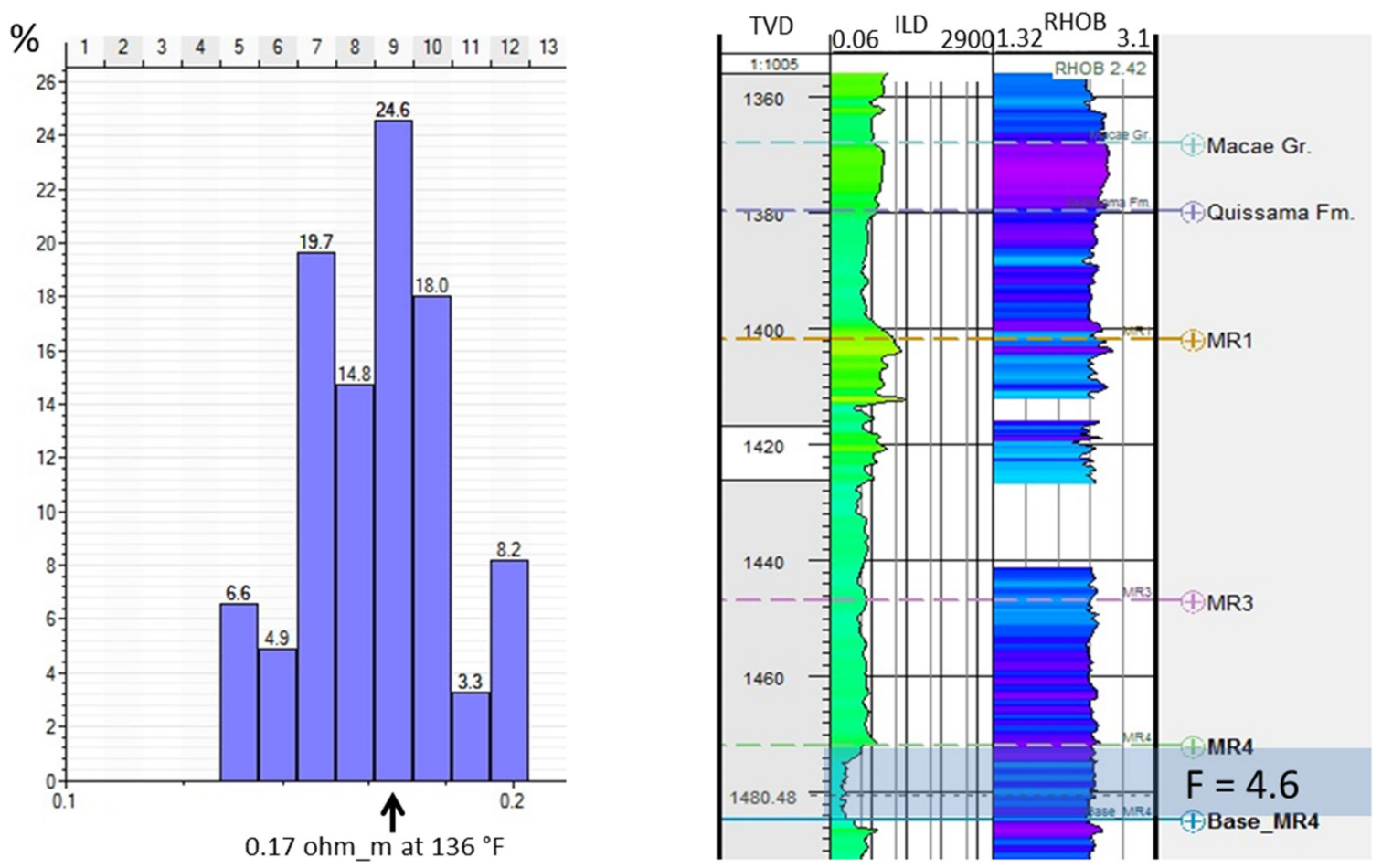

Figure 2. Frequency histogram showing the mode value for the $R_{\mathrm{O}}$ on the full water saturated reservoir (R4), as result $F=4.6$.

In this sense, for the same reservoir at the whole wells, $R_{\mathrm{O}}$ was calculated (at the full water saturation reservoir zone) based on the explained statistical sample (mode). The mode is justified because it is the most representative value of the total reservoir resistivity. Finally, using the predetermined $R_{\mathrm{w}}$ for each reservoir level, the value of $F$ was calculated. It is important to mention that from the whole interpreted reservoir levels (twelve) only R1 and R3 are oil saturated reservoirs, for these ten reservoirs were used for the analysis.

Thus, the water resistivity $\left(R_{\mathrm{W}}\right)$ value for Quissamã reservoirs were confirmed in $127 \mathrm{Kppm}$ (or 0.0377 ohm_m at $136^{\circ} \mathrm{F}$ ) as verified in the well folders. In this sense, the analyzed data (ten of the twelve identified potential reservoirs) was calibrated and compared with the measure of $R_{\mathrm{W}}$ value on the well RJS-0029-RJ. Based on this confirmation for Albian Carbonates reservoirs in the Campos Basin, it was assumed that this value would be applied for this kind of reservoir in the mentioned basin.

In order to achieve the goal of this work, the plot of resistivity factor versus porosity plot, initially defined for core analysis, was used with the porosity $(\phi)$ extracted from neutron wire $\log$ and the $F$ formation resistivity factor calculated as explained before (see table 1). As a consequence, the main parameters ' $m$ ' and ' $a$ ' were obtained by use of a $\log (\phi)$ versus $\log (F)$ graph (for the all selected reservoirs). In this sense the ' $m$ ' value is the slope of a linear relationship and ' $a$ ' is the ordinate interception as defined by Bassiouni (1994). The calculation is represented by the linear equation:

$$
\log F=\log a-m \log (\varnothing) .
$$

Table 1. Mode of formation resistivity factor and porosities calculated for each water saturated potential reservoir.

\begin{tabular}{llll}
\hline Reservoir & $F$ & Porosity & $R_{\mathrm{w}}\left(\mathrm{ohm} \_\mathrm{m}\right)$ \\
\hline R2 & 5.6 & 0.17 & 0.0377 \\
R4 & 4.6 & 0.19 & 0.0377 \\
R5 & 4.1 & 0.25 & 0.0377 \\
R6 & 5 & 0.17 & 0.0270 \\
R7 & 6 & 0.18 & 0.0270 \\
R8 & 7 & 0.15 & 0.0270 \\
R9 & 2.5 & 0.35 & 0.0270 \\
R10 & 4 & 0.25 & 0.0270 \\
R11 & 3.75 & 0.27 & 0.0270 \\
R12 & 10.6 & 0.1 & 0.0270 \\
\hline
\end{tabular}

\section{Results}

Four regional geological profiles were obtained and twelve potential reservoirs interpreted at the Quissamã Formation, as shown in figure 3 . From the total of 12 interpreted reservoirs, two contain hydrocarbons (R1 and R3) and they are not used for the determination of ' $a$ ' and ' $m$ ' parameters. Most of the identified reservoirs show almost the same thickness along the whole area. It was also observed that the reservoirs are separated by a fault system observed mainly at the east-west sections, caused by halokinetics tectonic and configuring listric faults compensated in a regional salt level (top of the Lagoa Feia Formation-Aptian age).

The $R_{\mathrm{o}}$ measured for the ten full water carbonate levels are related to salty water (usually associated with hydrocarbon). The well correlation is considered adjusted to the actual geological configuration, and this was confirmed by the 
NW

SE

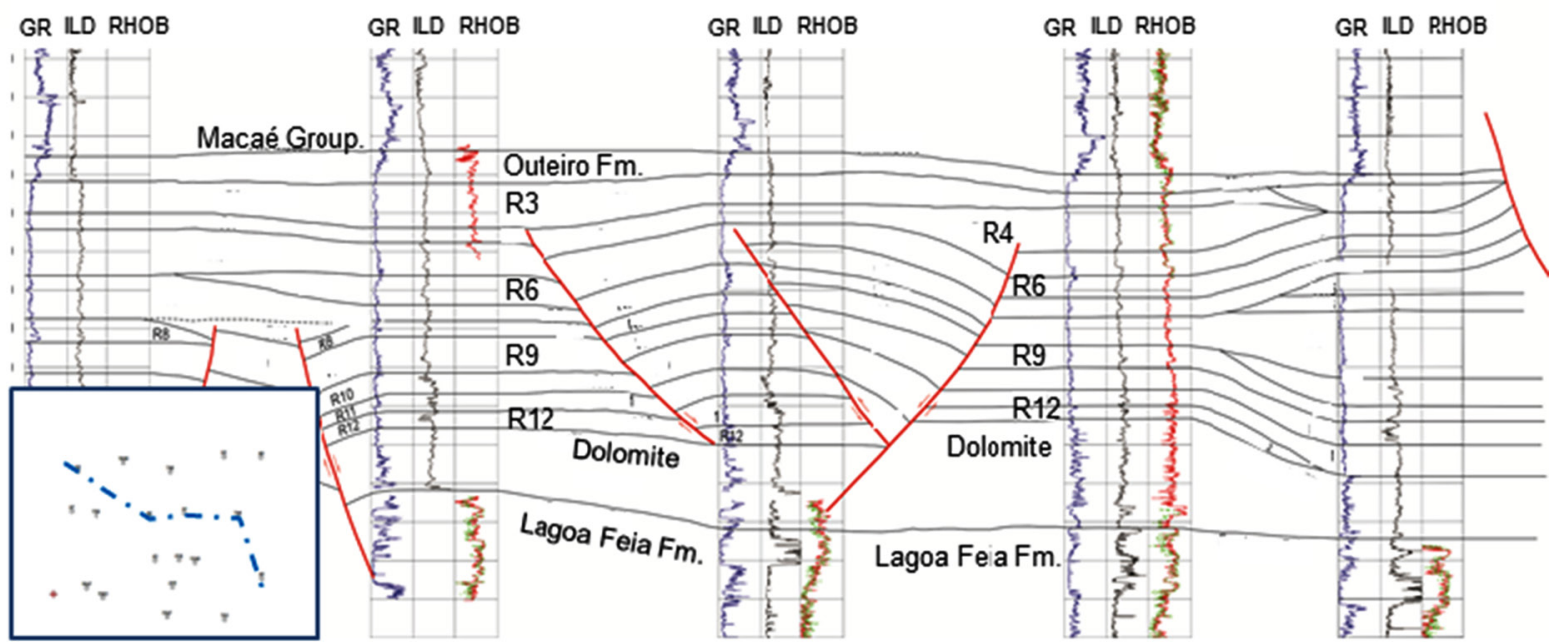

W

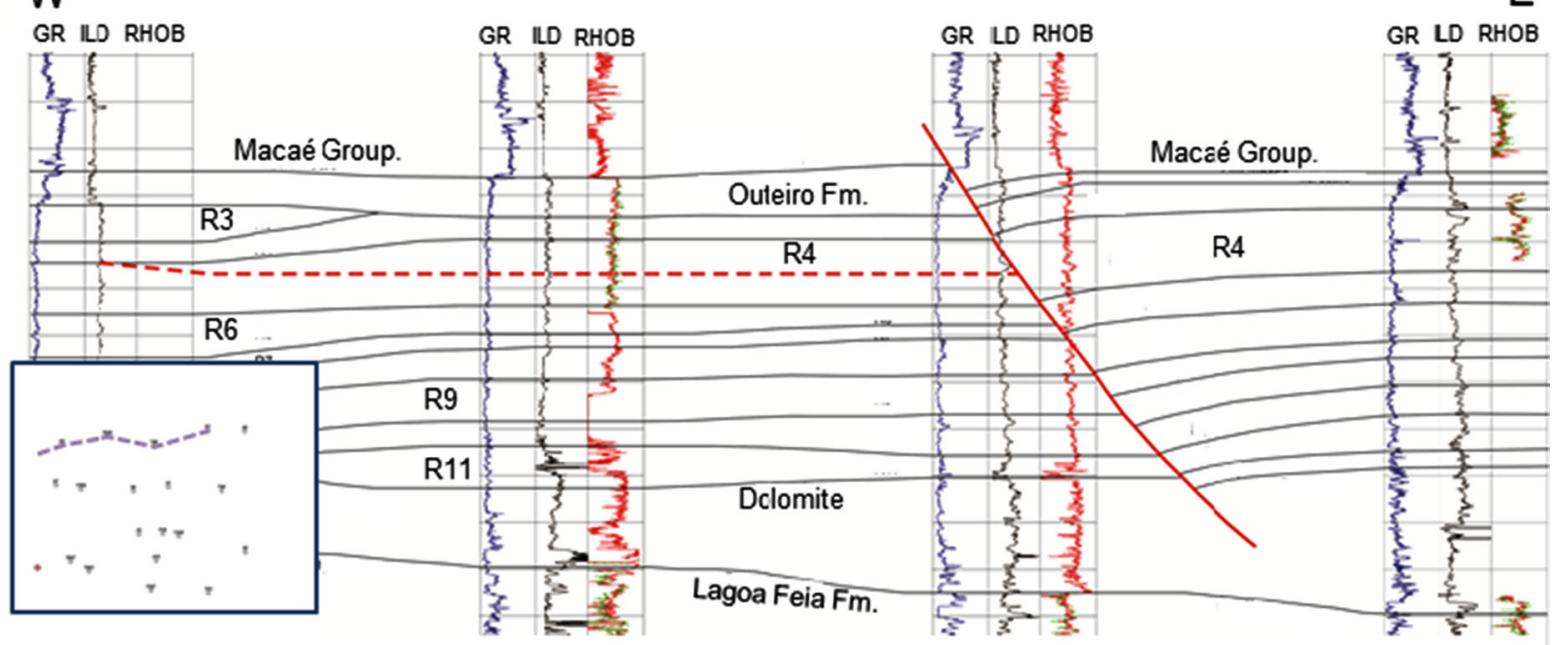

W

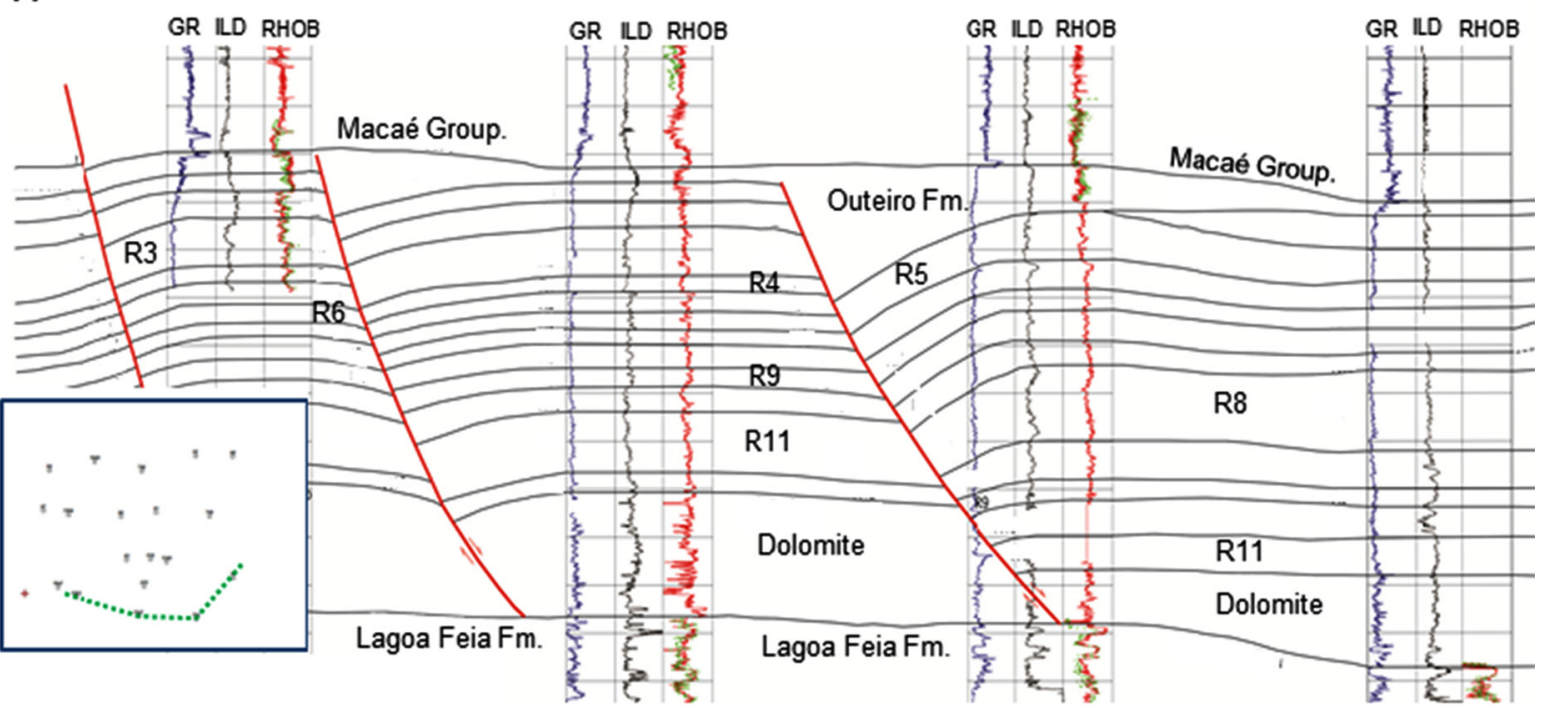

Figure 3. Geological profiles along the evaluated area showing the distribution of the twelve interpreted reservoirs and the ten stratigraphic levels filled by water (R2 and R4 to R12).

calculation of resistivity formation factor $(F)$ in some additional wells other than the reference wells. Based on the previous issue, it was necessary to add some faults that separate reservoirs at the geological interpreted configuration, and there were confirmed by seismic data as shown in figure 4 for the south profile (east-west profile). 


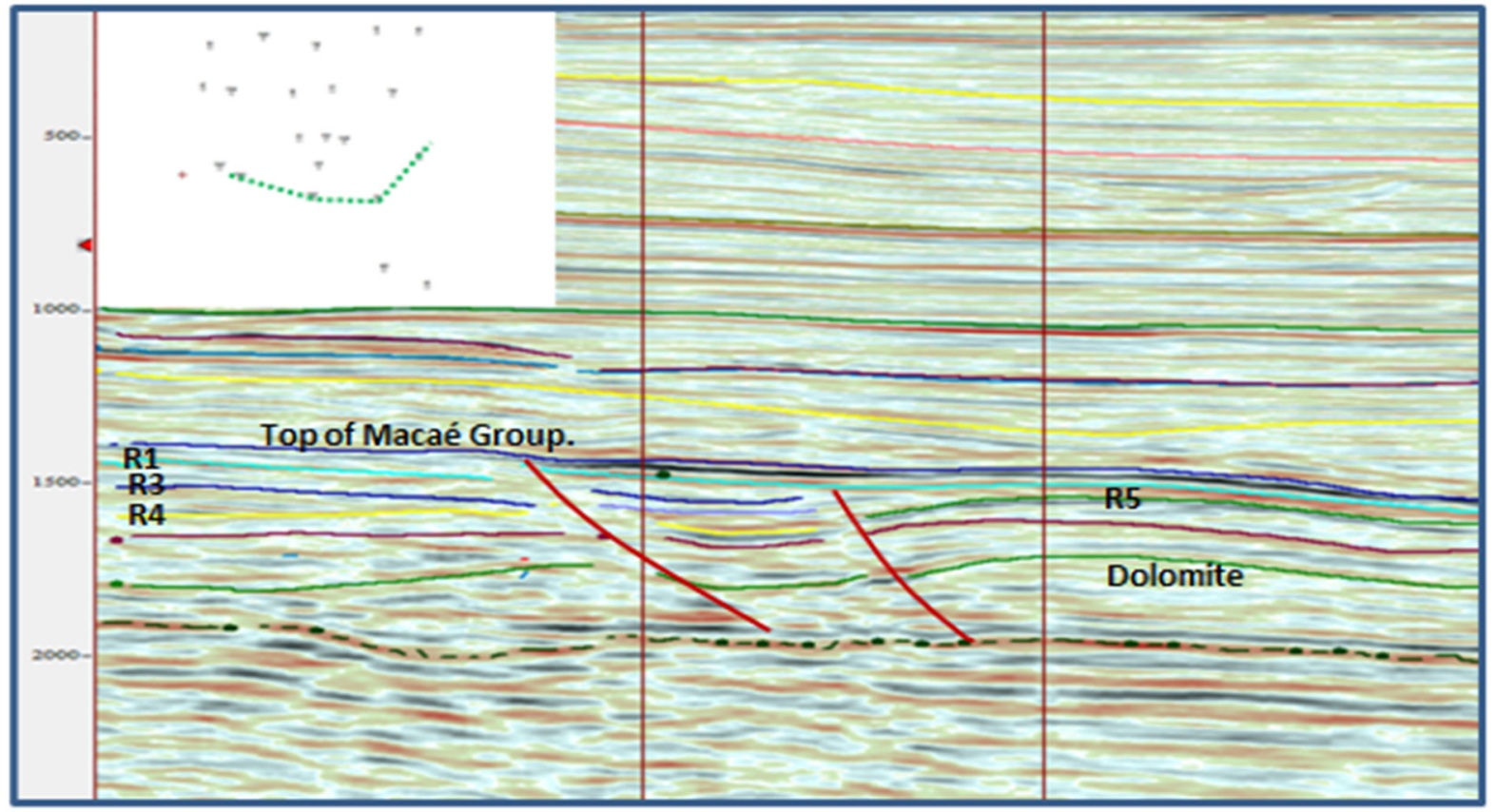

Figure 4. Seismic configuration for the listric fault system interpreted at the well correlation profiles (in this case the South one, green line at the maps). The seismic interpretation of some identified reservoirs like R1, R3, R4 and R5 are also shown. This seismic data does not show good resolution for identifying the whole reservoirs interpreted at the well data; the main use of this data was for structural control.

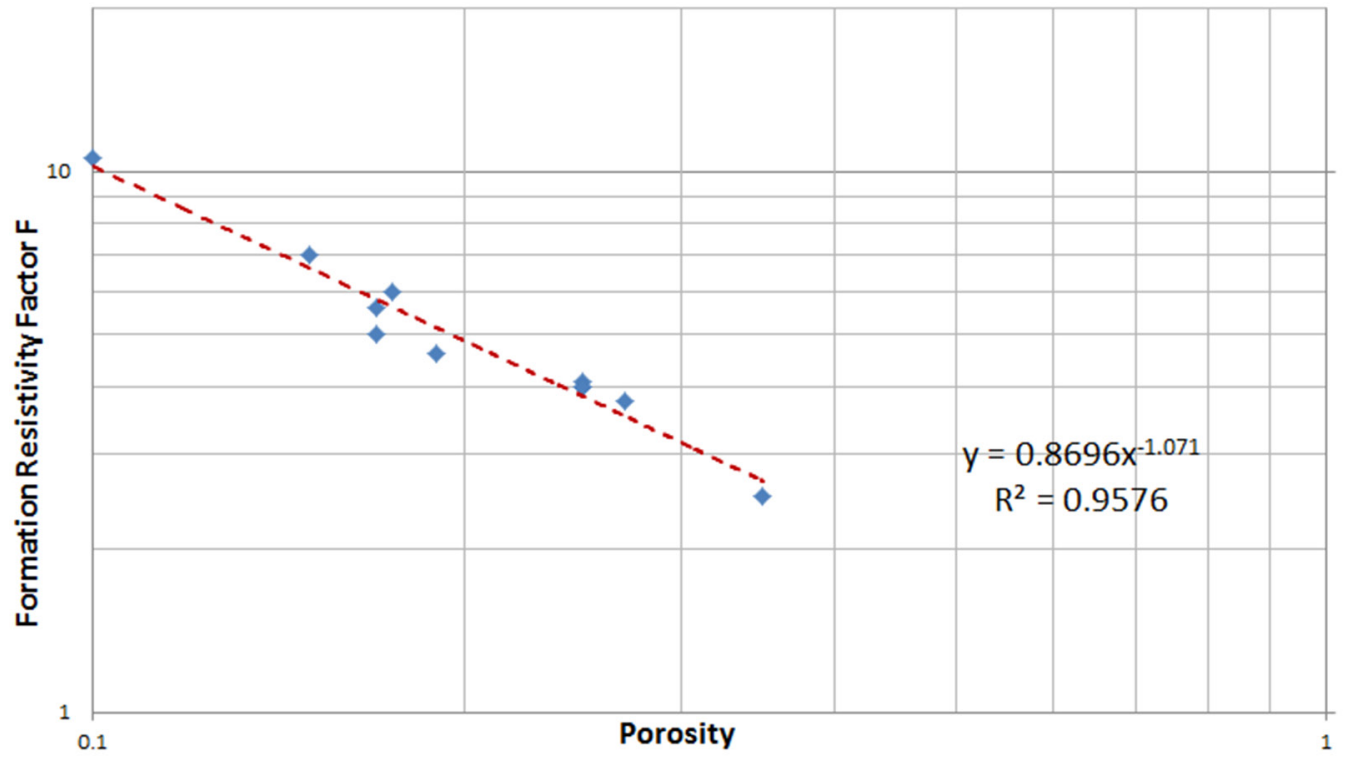

Figure 5. Log porosity versus $\log F$ graph. Observe the determination of the cementation $m$ non-dimensional value as 1.6 on the $x$ axis when the log porosity of the main reservoir is in theory 1.

The seismic section in two-way travel (time) vertical scale (figure 4), shows the top of the Macaé Group lowly deformed by the listric faults, confirming that the reservoir package at Quissamã Fm. defined by the letters $R$ are almost isopach in the region, but over this seismic data it is not possible to interpret the twelve reservoirs identified in well data, because of the seismic resolution. Even in this scenario it is possible to confirm the structural framework related to the own rheology of the Macaé Group_carbonate sequence separated in Outeiro Fm (Calcilutites), Quissamã Fm. (calcarenites-main reservoirs), and a regional Dolomite sequence at the base (non-reservoir at worked region).

All the calculations of the tortuosity and cementation values were done in a full water reservoir as in the Archie definition. As a result, the crossplot of $\log$ porosity versus $\log F$ was interpreted through the linear relationship amongst both factors by the defined equation $\log F=\log (0.8696)-1.071 \log \phi$, with $R^{2}$ calculated in 0.9576 , the ' $a$ ' value is non-dimensional equal to 0.8696 , and the ' $m$ ' value was determined as 1.071 as a non-dimensional value too (figure 5). An explanation for this 
would be related to that in the porous space of the carbonate rock, full fluid saturated, the electrical current travel as well as on siliciclastic rocks; because of this, the value is not 2 as traditionally used in low porosity's carbonates rock for Albian Brazilian carbonates reservoirs.

Related to water saturation $\left(S_{\mathrm{w}}\right)$, if it is calculated on a hydrocarbon reservoir like the R3 of the Quissamã Fm, using Archie's equation, and the tortuosity $(a)$ and cementation $(m)$ parameters as 0.8696 and 1.071 , respectively, for a reservoir with $R_{\mathrm{t}}=40 \mathrm{ohm} \_\mathrm{m}$ at $136^{\circ} \mathrm{F}$ (value measured on a resistivity $\log$ and corrected by the invasion effect), $R_{\mathrm{w}}=0.031 \mathrm{ohm} \_\mathrm{m}$ at $158{ }^{\circ} \mathrm{F}$ and $20 \%$ of porosity measured on the porosity log (NPHI) the water saturation is $6 \%$. However, if the same calculation is done using $a=1$ and $m=2$ the water saturation is $14 \%$, and as a consequence more hydrocarbon production is expected using the obtained parameters. This result was validated with the object reservoir production history.

It is important to mentioned that a higher porosity $(>20 \%)$ is necessary in order to get the actual saturation value using the obtained parameters. The consequence of using the traditional values for carbonate reservoirs with porosities higher that $20 \%$ is that this will impact on the economic evaluation of the interested reservoir, and the higher water saturation will lower the hydrocarbon calculated volume.

\section{Conclusions}

In conclusion, a water formation resistivity was determined in $127 \mathrm{Kppm}$ of $\mathrm{NaCl}$ for the main carbonate oil producer level on the Campos Basin. The values of the cementation and tortuosity factors are $m=1.071$ and $a=0.87$, respectively, when Archies's water saturation equation for carbonates reservoirs was applied.

When compared, the result of this calculation and the result using the default factors for carbonates reservoirs ( $m=2$ and $a=1$ ) concluded that the default values add high dispersion between the calculated water reservoir's saturation and the confirmed water production's reservoir history, in the case of high porosities carbonates reservoirs.
Finally, the use of the default ' $m$ ' and ' $a$ ' values in carbonate's reservoirs, with porosities higher than $20 \%$, will represent an over estimation of water saturation $\left(S_{\mathrm{w}}\right)$ that is less the calculated volume of hydrocarbon.

In summary, the value of cementation $(m)$ is higher affected by the pore configuration and size, and the tortuosity coefficient (a) appears to be a logical answer for carbonates reservoirs with high porosities, because it is the answer to the electrical current traveling through the interconnected pore system embedded by fluid.

\section{References}

Archie G 1941 The electrical resistivity log as an aid in determining some reservoir characteristics Petroleum Technology (Dallas Meeting, TX) pp 54-62

Bassiouni Z 1994 Theory, Measurement, and Interpretation of Well Logs (SPE Textbook Series vol 4) p 371

Hamada G, Almajed A, Okasha T and AlGathe A 2010 Uncertainly analysis of Archie's parameters determination techniques in carbonate reservoirs 2 nd Saudi Meeting on Oil and Natural Gas Exploration and Production Tecnologies (Dhahran, Saudi Arabia) OGEP 2010-161

Maute R E, Lyle W D and Sprunt E 1992 Improved data-analysis method determines Archie parameters from core data J. Pet. Technol. 44 103-7

Sharifi H G, Saadat K, Kazemzadeh E and Mahmoudian H 2012 Measurement of Archie parameters of some carbonate cores at full reservoir conditions J. Chem. Pet. Eng. 46 63-72

Simandoux P 1963 Measures diélectriques on milieu poreux, application a measure des saturations en eau, étude du comportement des massifs argileux Revue de L'IFP 193-215

Schlumberger 2009 Log Interpretation Charts 2009 Editions

Teixeira W S, Castillo V M G and Cáceres C S A 2015 Saturação de fluido nos reservatórios carbonáticos da Bacia de Campos: Equação de Archie e coeficiêntes de cimentação $(m)$ e tortuosidade (a) $14^{\circ}$ Simpósio de Geologia do Sudeste $/ 8^{\circ}$ Simpósio do Cretáceo do Brasil/VI Simpósio Nacional de Ensino e História de Ciências da Terra ANAIS-GEOSUDESTE-2015 (Campos do Jordão)

Waxman M H and Smits L J M 1968 Electrical conductivities in oil-bearing shaly sands $J$. Pet. Technol. 8 107-22 